\title{
DO WE KNOW WHAT CONTENTS WORK FOR SOCIAL COMMERCE? A CASE OF CUSTOMER ENGAGEMENT IN FACEBOOK BRAND PAGES
}

\author{
Mathupayas Thongmak \\ MIS Department, Thammasat Business School, Thammsat \\ University \\ mathupayas@tbs.tu.ac.th
}

\begin{abstract}
Social commerce is e-commerce empowered by social media. Good content strategy that takes into account what customers value is important to success, but very little is known about proper content types. The goal of this study was thus to understand the role of post quantity and content types in customer engagement on Facebook pages using content analysis to collect qualitative data and quantitative data. Content types were categorized into two categories and nine sub-categories according to the 4Ps theory along with uses and gratifications theory. More than 1,500 posts from 183 brand pages were analyzed to examine the relationships between overall posts per page in a week, the page's engagement, and popularity. The results represent the first attempts to explore content types with various established theories. The findings of this study could reflect the post types of brand pages by industries and guide brand page administrators toward effective content strategy.
\end{abstract}

Keywords: Facebook Brand Pages, Customer Engagement, Social Commerce, Marketing Mix, Uses and Gratifications

\section{INTRODUCTION}

The fact that social media now plays an important role in business is commonly known by companies around the world. Social media such as Facebook reaches a huge amount of online fans, providing opportunities for companies to conduct activities with prospective customers and strengthen relationships with existing ones ${ }^{1}$. Social commerce is a form of e-commerce merging social and commercial activities, empowered by social media ${ }^{2,3}$. 
Social commerce can refer to adding commercial features to social media, integrating social features into e-commerce platforms, or utilizing more social media by traditional companies ${ }^{4}$. It enables peer-customer interactions and customer-generated content such as ratings, reviews, recommendations, and referrals, which influence others' purchase decisions and shopping experiences ${ }^{4,5}$.

A product with a strong network effects has a large user base. Therefore, generating positive word of mouth is crucial for acquiring new customers $^{6}$. A Facebook fan page, sometimes called a Facebook brand page, can be used to create a network for sharing brand messages, extending customer networks, and collecting customers' preferences and feedback ${ }^{7,8}$. In this study, the terms fan pages and brand pages are used interchangeably. Managing brand social content to build social engagement is the mainstream ${ }^{9}$. A Facebook brand page with a well-designed social media marketing strategy could increase customers' word of mouth and customergenerated content ${ }^{10}$. Brand-related content should also be produced continuously to enable target audiences to engage with social media channels. The engagement or popularity of content could be reflected in liking, commenting, or sharing brand-related content ${ }^{10,11}$. Good content stimulates customer interaction ${ }^{10}$. Giving information about a product or service may create more demand or increase consumers' willingness to purchase or try a product or service ${ }^{12}$.

A survey by Deloitte's consumer products group indicated that consumers read others' product reviews online. Most of them normally share those reviews with friends, family, or colleagues ${ }^{12}$. Social media marketing thus should be aimed firstly at understanding customers; creating persuasive online content; identifying a proper strategy to build a strong brand; and enhancing customer-generated content ${ }^{10}$. In addition, according to the guidelines for a resonance marketing strategy, a company's senior management team should understand the effects of information on customers' preferences and behavior; know how to modify product offerings, pricing structures, product distribution, and promotional strategies to respond to those effects; and maintain the high ratings of the 
company's online community ${ }^{13}$. Hence, content engineering, which refers to seeking answers to the question "what content works best?", is important for online communities such as Facebook brand pages ${ }^{14}$.

Various online product presentation formats and post formats affecting user engagement were studied by Yi, Jiang, and Benbasat ${ }^{15}$, Valerio et.al ${ }^{16}$, and Sabate et al. ${ }^{10}$. It was found that taste-related information regarding consumer reviews should be given to customers to decrease their uncertainty about taste-related product ${ }^{17}$. In the study of Lee, Hosanagar, and Nair ${ }^{14,18}$, emotion and philanthropic content were determined to increase customer engagement, whereas informative content decreased engagement without persuasive content. Kim and Johnson ${ }^{19}$ found that positive brand-related user-generated content (environmental and informational content) encouraged brand engagement. It has also been shown that social currency, emotional posts, sports, retail, and useful content in posts generated by brands and publishers impacted user engagement in terms of shares ${ }^{9}$. Media types and content types were determined to affect stakeholders' engagement in local governments' EU Facebook pages ${ }^{20}$. Stephen, Sciandra, and Inman analyzed the Facebook posts of nine brands to extract content characteristics and consumer engagement. The most important content characteristic was persuasion ${ }^{21}$.

Although researchers have become increasingly interested in customer engagement on social media platforms, studies in this area are still lacking, largely fragmented, and at the beginning stage ${ }^{22-25}$. Empirical research examining the influence of social media content on customer engagement is also rare ${ }^{20,21,26}$. Moreover, none of the studies has explored an integrated picture of social media content (uses and gratifications theory and the established marketing-mix theory) and the complete set of customer engagement (total likes, total comments, and total shares). Only a few studies have looked at enjoyment content together with informational content. Many of the studies have collected data from only a few brand pages in some brand categories. The goal of this study was thus to address these research gaps with the following research questions: Do Facebook posts increase customer engagement? If so, how do the 4Ps and other posts 
impact total post popularity? Does customer engagement affect brand awareness and interaction in terms of People Talking About This (PTAT)? PTAT is a key metric combining all interactions with a fan page such as page likes, likes, comments, shares, RSVP's, and check ins ${ }^{27}$. Finally, do brand awareness and interaction extend the fan base of Facebook brand pages in terms of new likes?

\section{RELATED WORK}

\subsection{Facebook Brand Pages, Customer Engagement, and}

\section{e-WOM}

Social media dominates business and personal lives nowadays ${ }^{28}$. It gives some advantages to marketers, for instance, enhancing customer loyalty, creating marketplace intelligence, exposing companies to new markets, increasing sales, decreasing costs, and promoting efficiency ${ }^{1,27}$. Facebook provides five tools to support social commerce, which are Facebook ads, Facebook fan pages, social plugins, Facebook applications, and sponsored stories ${ }^{24}$. A Facebook fan page or brand page was a tool introduced in November $2007^{20}$. It allows a company to create added value for its brand and customers, to advertise new promotions, to ask questions, and to promote its products or services with posts containing anecdotes, photos, videos, or other materials ${ }^{20,29,30}$. It also allows users to control the content shown and brand experiences by choosing to be informed about the brands they like ${ }^{26}$. A brand community, such as a Facebook brand page, is vital for boosting sales, managing customer relationships, creating brand loyalty, gathering customers' opinions about a brand, and engaging customers in word of mouth communication ${ }^{24,27,31,32}$. Positive attitudes towards social media could lead to greater purchasing frequency, buying quantity, and customer expenditures ${ }^{33}$.

Interactions within a brand page reflect a part of a firm's customer relationships ${ }^{30}$. A Facebook brand page enables customers to interact with the company by adding or liking content on the page's wall, giving comments on existing wall posts, or sharing the posts with their peers ${ }^{24}$. 
Different brand-related activities conduce to different levels of engagement. Liking comments or posts provides positive feedback to brand page administrators. Commenting on posts shows that fans move from being observers to media contributors, showing their interest and supporting others to share their opinions and knowledge. Uploading product pictures or sharing brand posts mean that they are brand-related content creators, agreeing with the brand messages ${ }^{11,}{ }^{16}$. Liking is a form of positive attitudinal response. Comments and shares are marketing outcomes, as same as feedback and electronic word of mouth (e-WOM), respectively ${ }^{21}$. Engagement is also defined as the average number of likes, comments, and shares per post $t^{34}$. This affects purchase intention and the sales of products or services in social commerce ${ }^{2,15,35}$.

Electronic word of mouth is positive or negative statements about products or services presented by customers, relevant users, and potential consumers, which are made available online ${ }^{31,36,37}$. E-WOM could enable companies to achieve marketing goals such as promoting new products or services, increasing brand awareness, building the brand image, increasing the firm's stock performance, and reaching global audiences ${ }^{19}, 24,26,38$. Good content or good messages generate positive e-WOM [21]. The more positive user-generated content that appears, such as product reviews, the more sales volume will be gained ${ }^{37}$. Therefore, a firm owning a brand community should draw its fans' intention and sustain social interactions within the page regularly with influential and relevant content ${ }^{8}$.

\subsection{Uses and Gratifications of Content: Marketing-Mix}

\section{Information and Others}

Uses and gratifications theory is a widely accepted theory regarding mass media and the adoption of communication technologies, which holds that consumers use content or media for certain purposes ${ }^{39-41}$. Gratification received from content consists of informativeness, playfulness (or enjoyment), and interactivity ${ }^{42}$. Gratifications obtained from the frequency of Facebook use and Facebook profile updates include passing time, affection, sociability, and social information ${ }^{43}$. Gratification received from 
Facebook group uses relates to socializing, entertainment, self-status seeking, and information seeking ${ }^{44}$. Uses and gratification themes extracted from social media are social interaction, information seeking, passing time, entertainment, relaxation, communicatory utility, convenience utility, expression of opinions, information sharing, and surveillance/knowledge about others ${ }^{45}$. According to a framework for consumer behavior in social commerce, content characteristics (informational content, entertaining content, and others) affect purchase and post-purchase behavior, moderated by content type ${ }^{3}$. Information and entertainment seeking are drivers to engage brand communities ${ }^{46}$. Content types (entertainment and information) affect the likes ratio. Entertainment, information, and remuneration content have an influence on the comments ratio. Entertaining content also boosts the sharing ratio, whereas content types (entertainment and information) enhance the interaction duration ${ }^{24}$. Adding emotional content in fan page posts is also useful for service companies to promote e- $\mathrm{WOM}^{47}$. In addition, users sometimes share a post on Facebook because it makes the sharer look good or intelligent ${ }^{9}$.

The traditional marketing-mix concept (4Ps) can be extended to the informational aspect of content types since this framework dominates marketing management, helping firms meet their customers' needs and expand sales territory ${ }^{48-51}$. The marketing-mix framework contains four key components: product, price, place, and promotion ${ }^{52}$. Products are the diversity of commodities, goods with well-recognized brands, good quality, or attractive package, to satisfy customers ${ }^{48,52,53}$. Information about a product consists of product performance, design, quality, features, and so $\mathrm{on}^{54}$. Product design should depend on strong consumer preferences ${ }^{13}$. The richness of information about products or brands generated by users impacts other consumers' purchase behavior ${ }^{55}$. To acquire products or services, customers have to afford some costs, called price ${ }^{53}$. Price is determined by customers' willingness to pay ${ }^{13}$. Price could refer to cheaper prices of products compared to others, discounts, credit purchases, or purchases by installments ${ }^{52}$. Information about prices includes affordability, discounts, special prices, and credit facilities ${ }^{54}$. Place consists of online or 
offline channels for acquiring products or services, but nowadays place is generally online from everywhere for everyone ${ }^{13}, 53$. Brand pages, especially B2C, should add information about places such as direct calls to buy in their posts to enhance e- $\mathrm{WOM}^{47}$. Information about places relates to product availability, products sold, customer services, and special warranties by dealers, etc. ${ }^{54}$. Promotion concerns the benefits received from purchasing products or services ${ }^{53}$. This is increasingly specified by online customer-generated content ${ }^{13}$. Examples of promotions are advertisements, sales promotions, exchange offers, buy back offers, and free gifts ${ }^{54}$.

\section{REASEARCH APPROACH - HYPOTHESES}

\subsection{Facebook Posts: Marketing-mix Information versus}

\section{Others}

The right content strategy drives fan engagement ${ }^{8,24,30,47,56}$. Brand posts, including various content types (images or videos), generate significantly higher levels of post popularity ${ }^{10}$. The importance of content types and content agility on brand community engagement (the number of likes and comments) of Indian higher education institutions was statically supported $^{8}$. It was determined that the popularity, commitment, virality, and engagement of citizens vary according to media types (videos, links, photos, texts, and others ${ }^{20}$. Post formats are significantly relevant to digital engagement. Images increase the number of likes more than plain text, while plain text and images generate more comments than links. Videos are also more likely to be shared than links or plain text posts ${ }^{16}$. Posts including one or more links to other websites significantly increase likes, reach, comments, and shares ${ }^{21}$. According to Facebook marketing research, photos, videos, and status updates are the top three message types, which obtained the highest number of likes and comments, respectively ${ }^{18}$. Content characteristics (arousal-oriented, persuasion-oriented, information, calls to action, references, and media elements) tend to affect attitudinal responses (positive, negative), which possibly impact marketing outcomes (brand exposure, feedback, WOM, and website traffic referrals) and are moderated 
by an audience mix (narrower vs. broader) ${ }^{21}$.

Informational support positively influences community commitment ${ }^{57}$. Informative content is vital for online community engagement ${ }^{24}$, 58-60. Informative posts could make people forward the posts by giving likes or sharing on wall posts ${ }^{56}$. People consume brand-related content because of the pursuit of information ${ }^{60}$. People also use social media and participate in a Facebook community due to information seeking ${ }^{30,61}$. Informational content in a message, which has usefulness value, stimulates consumers to forward that message on social networking sites ${ }^{9}$. Consumers frequently lack product-related information to complete their buying decisions ${ }^{55,62}$. Directly informative content drives click-through rates, which significantly increase likes and comments when personality-related brand content appears together in a message. Directly informative content could refer to content about a specific brand, a specific product, deals, price match guarantees, product prices, targeting an audience segment, product availability, or product location ${ }^{14}$. Providing product-related information drives likes ${ }^{21}$. Posts mentioning product-related information such as uses, benefits, and new products or extensions increases the number of likes and reach. Posts mentioning value-related information such as pricing, discounts, and coupons boost the number of likes and comments. Posts with an advertising tone affect attitudinal responses in terms of likes and impact marketing outcomes with respect to comments and shares ${ }^{21}$. Customers normally seek discounts or coupons and read reviews or product rankings before making purchase decisions ${ }^{1}$. In terms of online product presentations, full product interaction design results in more user engagement than restricted product interaction design, whereas restricted product interaction design leads to higher user engagement than non-interactive design ${ }^{15}$. Information about the product and place significantly impacts customers' buying and decision-making behaviors ${ }^{54}$. Information about product availability, product location, and specific products obtains the highest number of likes and comments $^{18}$. A combination of marketing-mix information can increase user-generated content ${ }^{37}$.

Creating more brand-related information affects the number of likes, 
comments, and interaction on a Facebook brand page ${ }^{24,30}$. Giving general brand-related information for narrow audience mixes helps to increase likes. Posts that are perceived as being relevant to the brand and posts that mention news about the brand (general information and/or information about brand-related events) drive the number of likes, comments, and shares. Referring to non-brand information and linking to external websites positively affect the number of likes. Posts referring to non-brand entities such as sponsorships and charities positively impact attitudinal responses in terms of likes and impact marketing outcomes with regard to comments, shares, and clicks. Humorous posts also have a significant influence on likes and shares ${ }^{21}$. Brand-related user generated content statistically influences emotional responses such as pleasure, arousal and cognitive responses in relation to consumers' perceptions of information quality. These responses then positively impact content pass-along, impulse purchases, futurepurchase intention, and brand engagement ${ }^{19}$. Brand personality-related content has a positive influence on social media engagement (likes and comments). Brand personality-related content can be messages containing remarkable facts, emotional presents, emoticons, information about holidays, humor, philanthropic/activist messages, small talk/banter, or answers to questions ${ }^{14}$. Content triggering emotions are likely to be shared by more consumers ${ }^{9}$. Emotional content receives the highgest number of likes and comments ${ }^{18}$. Entertaining content is crucial for online community engagement ${ }^{24}$, 58-60. Entertainment value was found to positively drives Brazilian youths' Facebook participation ${ }^{41}$. It also impacts consumers' positive attitudes towards ads and encourages consumers to engage with online brand-related content ${ }^{30,60}$. A higher number of likes, comments, and longer interaction duration can be achieved by posting more entertainment content ${ }^{24,30}$. Therefore, the following hypotheses are presented:

H1: For each brand page, more posts will increase the sum of (a) likes, (b) comments, and (c) shares.

H2: For each brand page, there is a positive relationship between marketing-mix posts and the sum of (a) likes, (b) comments, and (c) shares. H3: For each brand page, there is a positive relationship between other 
posts and the sum of (a) likes, (b) comments, and (c) shares.

\subsection{Likes, Comments, Shares by Facebook Users}

Consumers engage with a brand page in the form of likes, comments, or shares ${ }^{24}$. When a fan likes, comments, or shares a message, it will normally appear in the news feeds of others. Consequently, the message creates e-WOM and results in more customer engagement ${ }^{30,63}$. The likes of Facebook represent the aggregated opinions of social commerce consumers. This can help other consumers cope with information asymmetry and quality uncertainty ${ }^{2}$. Liking a brand post also means a consumer endorses the post for their friends ${ }^{47}$. Positive comments on a brand message positively impact the message's popularity (likes and comments) ${ }^{30}$. The number of YouTube comments in the first 15 days significantly impact a video's popularity in terms of total views 60 days later ${ }^{64}$. Sharing content has a greater influence on the content's popularity than liking and commenting behaviors because it results in non-fans of a brand page seeing that content on their Facebook feeds ${ }^{27}$. Content contribution significantly drives consumers' engagement with brand-related social-media content in the form of commenting on videos, posts, or pictures related to a brand, sharing a brand related posts, or liking pictures or posts related to a brand. Creation can be initiating posts related to a brand, posting pictures or videos related to a brand, or writing posts or reviews related to a brand ${ }^{11}$. There is a relationship between consumers' brand-related participation in social networking systems (Facebook, Twitter, Instagram or Snapchat) and the identification, engagement, commitment, and membership intention of brand community-related outcomes. The relationship is moderated by an attention to social comparison, trust, tie strength, and homophile of social networking systems ${ }^{65}$. Therefore, the following hypothesis is presented: H4: For each brand page, the sum of (a) likes, (b) comments, and (c) shares increase the highest PTAT.

\subsection{People Talking About This}

Facebook group members tend to have more positive attitudes towards 
advertising of brands than non-members ${ }^{31}$. A single brand engagement from a member such as liking can create a social contagion effect, which is referring a post to friends in the member's social network ${ }^{47}$. Strong engagement of group members can boost brand popularity, creating more reaches on brand posts. People Talking About This (PTAT) represents the brand page's history in terms of awareness and interaction ${ }^{27}$. PTAT combines stories such as liking, commenting, or sharing posts, answering a question, responding to an event, or claiming an offer ${ }^{66}$. Total fans show the reachability of social media sites ${ }^{67}$ and the total fans of a brand page indicate the page's size. Facebook advertisements use page size as one of the key indices indicating the success of advertisements. The number of fans who like a fan page can also be used to appraise the growth rate of a brand community from time to time ${ }^{27}$. Therefore, the following hypothesis is presented:

H5: The highest PTAT increases newer likes in Facebook brand-fan pages.

\subsection{Study Design}

The sample for this study was 210 brand communities built on Facebook pages in Thailand, both local and international brand pages, under the conditions that the selected brands must have concrete products or services provided for customers and their brand pages must be listed as top brands in each category according to Socialbakers.com ${ }^{68}$. The Facebook platform was the focus due to having the highest number of users among social media, its availability, and its user-friendly features such as statistics for a fan page, which enabled the research assistants to easily collect both qualitative and quantitative data. The selection process is shown in Figure 1. 
-Investigating top 100 brand pages with the highest fans from

Socialbakers.com on February $2013^{71}$

100 pages

- Choosing more brand pages within the same categories, with the same proportion as the brands in each category in the top 100

210 pages brands, to add more samples

-Replacing some brand pages that are unavailable.

Figure 1. Brand page source selection process

Table 1. Page sources categorized by brand categories

\begin{tabular}{lc}
\hline \multicolumn{1}{c}{ Brand category } & Total collected pages \\
\hline $\begin{array}{l}\text { Fast-Moving Consumer } \\
\text { (FMCG) }\end{array}$ & 52 \\
\hline E-commerce & \\
\hline Retail food & 25 \\
\hline Telecommunications & 6 \\
\hline Electronic & 25 \\
\hline Fashion & 30 \\
\hline Financial & 23 \\
\hline Jewelry \& watches & 4 \\
\hline Retail & 15 \\
\hline
\end{tabular}

The total selected pages are shown in Table 1. A company may have one or more brand pages to communicate with its customers and gather customer feedback and information on expectations ${ }^{47}$. The classification of brand categories was based on the brand categories listed in Socialbakers.com ${ }^{69}$. Data was gathered over a period of seven months from June 2013 to December 2013. Wall posts in a week with the highest PTAT showing brand awareness and interaction were collected. The focus was on 
the week before the date with the highest PTAT of each page because this should be when the page receives more interaction. The accumulated data was both qualitative (post types) and quantitative (current number of fan likes, the highest PTAT, new likes per week, the number of likes, the number of comments, and the number of shares). The number of likes, comments, and shares represented the engagement of users on a Facebook page ${ }^{20,34}$. Likes and comments also indicated the content's popularity ${ }^{10}$. Likes, comments, and shares also reflected attitudinal response, feedback, and eWOM, respectively ${ }^{21}$.

Data were collected by two research assistants familiar with the marketing-mix concept. Data collection was performed using the guidelines given by the main researcher. The analysis of qualitative data was based on content analysis and manual coding was used to transfer the qualitative data to quantitative data. The guidelines consisted of the definition of post types and suggestions on how to collect and verify data. Due to the massive number of brand page posts, brand pages were divided into two sets and the research assistants were assigned to collect the data individually. It was suggested that the research assistants check the Facebook page links and record links that were not found. Both research assistants were also required to jointly make judgments on unclear posts and randomly validate the data collected by the other research assistant.

A Facebook brand page was the unit of analysis in this study. Facebook wall posts on each brand page were extracted according to the classification of post types as follows. In light of the research purposes and literature review $^{54,70}$, this work focused on the concept of 4Ps together with uses and gratifications. Thus, two main categories, i.e., marketing-mix posts and other posts and their sub-categories, were used for coding. For marketingmix posts, the sub-categories were $\mathrm{p} 1$ : product, $\mathrm{p} 2$ : price, $\mathrm{p} 3$ : place, and $\mathrm{p} 4$ : promotion. A post giving a detailed narrative about a product was considered as a product post. A post giving information about price was considered to be in the price category. A place post was about the channels used to acquire products or services. A post mentioning discounted prices, redemption points or gifts, coupons or gift cards, persuading fans to 
participate in product-related events and giving free products or premiums was classified as a promotion post. For other posts, the sub-categories were o1: brand-related information, o2: brand-unrelated information, o3: emotional posts, 04 : social posts, and 05 : entertaining posts. A post giving information or knowledge about a brand, but not about its products or services, was considered a brand-related information post. A post presenting interesting information or knowledge unrelated to a brand was categorized as a brand-unrelated information post. A post affecting emotions other than entertaining, e.g., angry or sad, was considered an emotional post. A post encouraging fans to give opinions or join productunrelated events was classified as a social post. An entertaining post was a fun, relaxing, or enjoyable post. Each post was categorized by type according to the main theme under which it fell.

In order to examine the propositions, collected posts and their attributes were combined for each brand page. Customer engagement in terms of likes, comments, shares was also computed to determine the impact of posts and post types (marketing-mix posts vs. other posts). The effect on awareness and interaction was also evaluated. In addition, the influence of awareness and the interaction of brand pages on brand page growth were analyzed. Descriptive statistics, simple regression, and multiple regression were applied to test the propositions as appropriate.

\section{RESEARCH FINDINGS}

\subsection{Descriptive Statistics}

Of the 210 brand pages specified in the previous section, there were 183 brand pages left for data collection because 27 brand pages were not available or did not contain posts in the specified time period. Brand pages were classified into nine groups according to Socialbakers.com ${ }^{69}$. As shown in Figure 2, there were 51 pages from Fast-Moving Consumer Goods (FMCG), 23 pages from e-commerce, 19 pages from retail food, four pages from telecommunications, 24 pages from electronics, 26 pages from fashion, 19 pages from finance, three pages from jewelry and watches, and 14 pages from retail. The final database consisted of 1,577 posts, which were used 
for the data analysis. The average fans per page in each category was calculated as shown in Figure 2 because the data were collected from many pages in each category and each page in each category had a different numbers of fans. Of 183 brand pages, there were 648,084 average fans per FMCG brand page, 217,323 average fans per e-commerce brand page, 180,305 average fans per retail food brand page, 465,709 average fans per telecommunication brand page, 276,935 average fans per electronic brand page (excluding one outlier brand), 114,626 average fans per fashion brand page, 131,342 average fans per finance brand page, 69,953 average fans per jewelry and watches brand page, and 208,149 average fans per retail brand page.

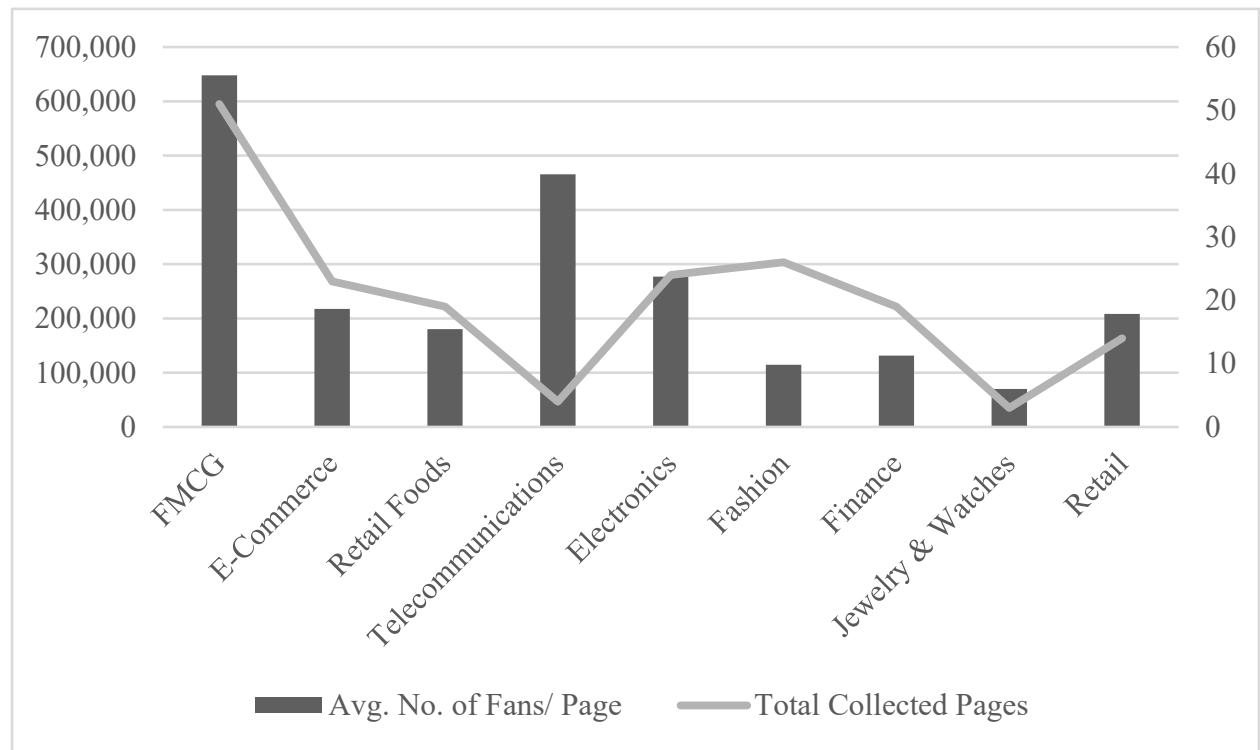

Figure 2. Total collected pages and the average fans per page for each brand category

Social content sharing on Facebook brand pages impacted the perception of readers about the usefulness of content differently according to product categories (beauty, publishing, games, food/beverage, and retail) $)^{9}$. Message content appearances such as emotion, holidays, humor, deals, etc., varied considerably among different industry categories (websites, places, organizations, entertainment, consumer products, and celebrities) ${ }^{18}$. For all post types, the most active brand groups were FMCG and e-commerce brand pages, which had 15-16 posts per week on average. 
The retail brand pages posted approximately seven posts per week. Brands in the remaining categories created content on an average of 3-4 posts per week.

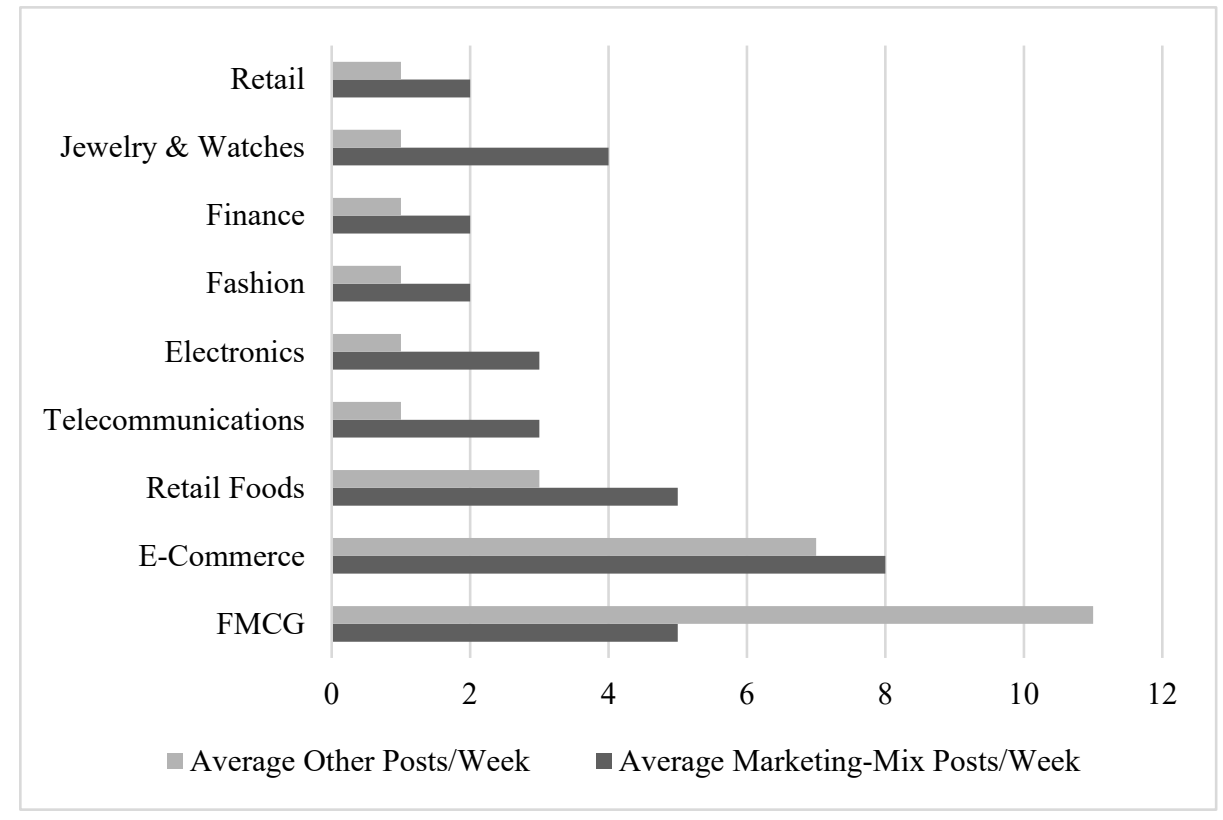

Figure 3. Average 4Ps Posts and Other Posts per Brand per Week, Classified by Brand Category

Each page in the same brand category posted different content. Figure 3 gives an overview of posts classified by two main content types: marketing-mix posts and other posts, indicating the average posts per week of all the brands in each category. Clearly, all pages in almost every category except FMCG brands focused on giving marketing-mix information, particularly e-commerce brands, which posted eight messages per week on average. FMCG, e-commerce, and jewelry and watch brand pages gave 4Ps information at the same proportion, that is around 4-5 posts per week. Jewelry and watches, telecommunications, and retail food brand pages gave precedence to marketing-mix information over other posts and communicated 4P content more than other content at approximately 2-3 posts per week. FMCG brands concentrated on other posts, presenting other message content more than $4 \mathrm{P}$ content at the average of six posts per week. 

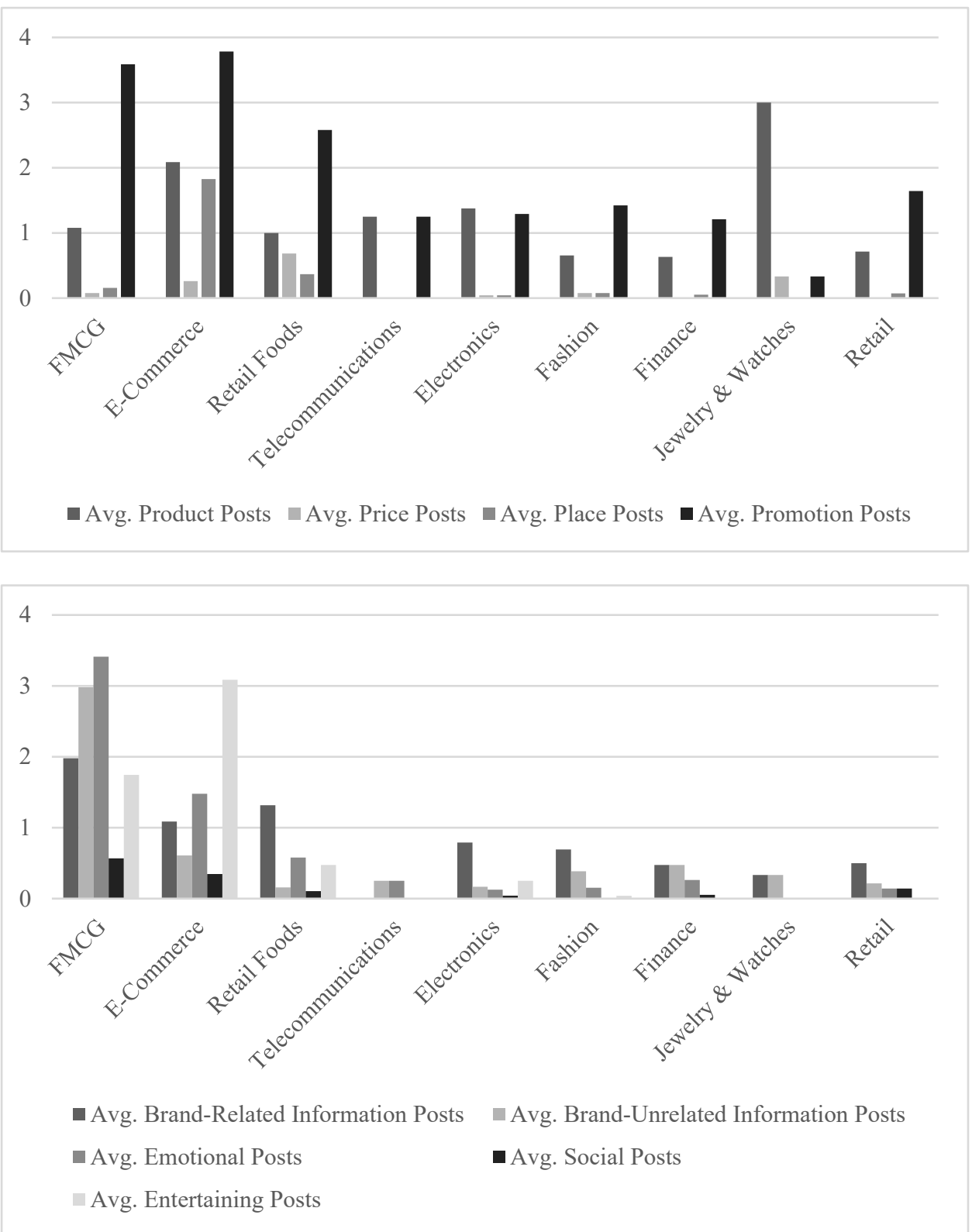

Figure 4. Details of Average Posts per Week, Classified by Post Types and Brand Categories

Regarding the details of the marketing-mix posts and other posts as shown in Figure 4, the common post types were promotional posts, product posts, and brand-related information posts. Brand pages in every category except jewelry and watches regularly gave information about promotions, especially FMCG, e-commerce, and retail food brands, which posted 3-4 
messages per week.
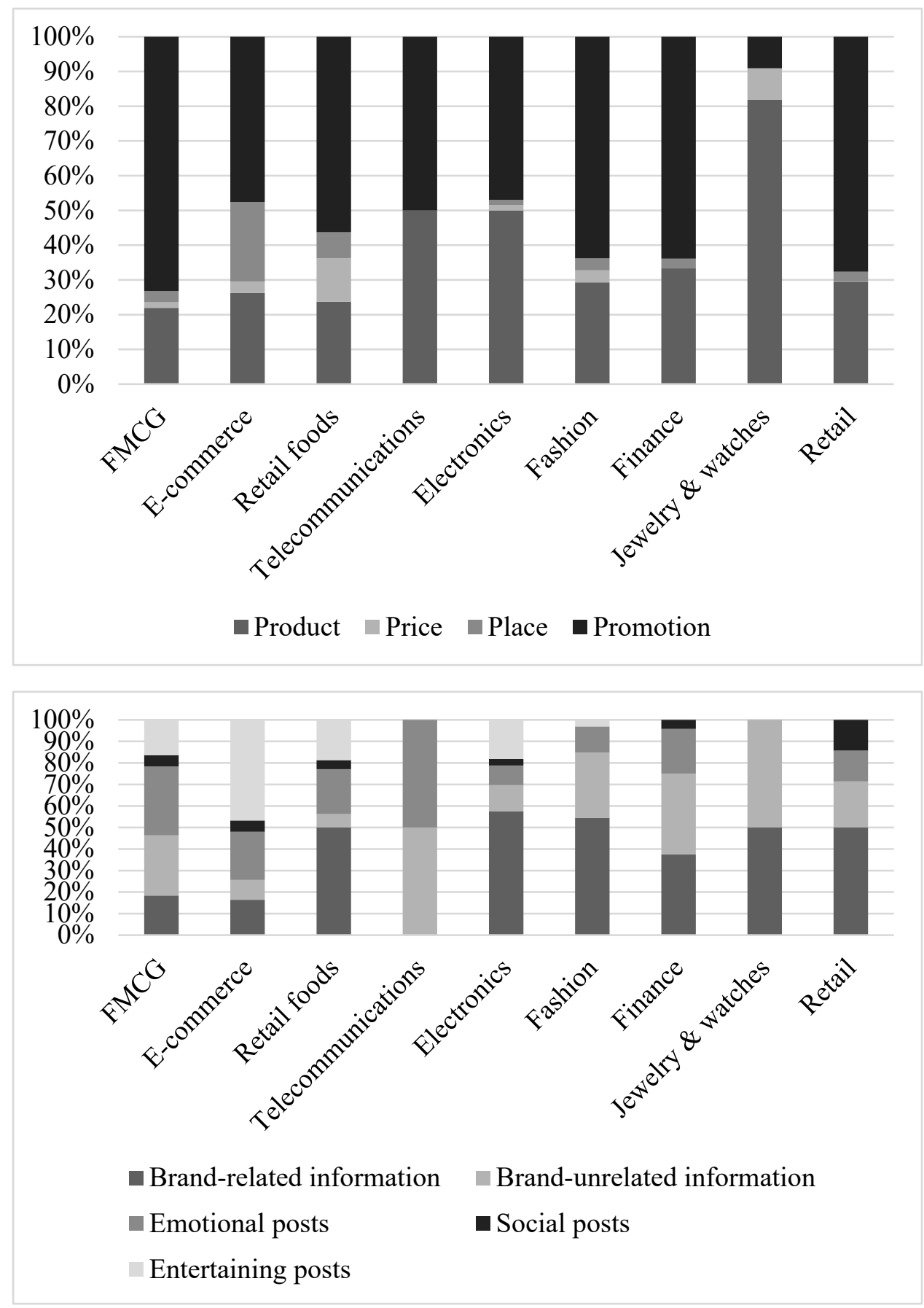

Figure 5. Percentage of Each Post Types in Each Week, Classified by Brand Category

Telecommunications, electronics, fashion, finance, and retail brand pages 
used promotional posts to persuade their fans to participate with around 12 posts per week. Product posts were utilized in every brand category, particularly jewelry and watches. Jewelry and watches posted content about their products approximately three time per week, whereas pages in other brand categories shared 1-2 posts about their products per week on average. E-commerce brand pages gave place information in around two posts per week. Retail food brands presented information about prices in posts (how many?) per week.

From the highest number of other posts per week of FMCG brands, the content was related to brand-unrelated information/emotional content ( 3 posts per week), brand-related information/entertainment ( 2 posts per week), and social content (1 post per week), respectively. E-commerce brand pages frequently used entertaining posts ( 3 posts per week) and normally applied brand-related information posts, brand-unrelated information posts, and emotional posts (1 post per week). Retail food, electronics, fashion, and retail brand pages generally gave brand-related information in one message per week. Retail food brand pages also created an emotional post once per week. However, telecommunications, jewelry and watches, and finance brand pages rarely applied other content types to promote their pages.

Figure 5 shows the percentage of marketing-mix information posts and other posts categorized by brand groups. Of 1,591 posts from 183 brand pages, including some posts that fell into more than one sub-category, 736 posts were about marketing-mix information and 855 posts were about other content. These posts were later summarized according to each brand page to be used as input for the next phase. Considering the marketing-mix posts, 250 posts belonged to FMCG brand pages, 183 posts belonged to Ecommerce brand pages, 88 posts belonged to retail food brand pages, 66 posts belonged to electronic brand pages, 58 posts belonged to fashion brand pages, 36 posts belonged to finance brand pages, 34 posts belong to retail brand pages, 11 posts belonged to jewelry and watches, and 10 posts belonged to telecommunication brand pages. In terms of marketing-mix information, 439 posts were promotional posts, 208 posts were product 
posts, 62 posts were posts about distribution channels, and 27 posts were about prices. Almost all brand types heavily gave information about promotions except the brand pages of jewelry and watches. Product information was also popular information given by every brand page, especially jewelry and watches.

Considering the other posts, 545 posts belonged to FMCG brand pages, 152 posts belonged to E-commerce brand pages, 50 posts belonged to retail food brand pages, 33 posts belonged to electronic brand pages, 33 posts belonged to fashion brand pages, 24 posts belonged to financial brand pages, 14 posts belonged to retail brand pages, two posts belonged to telecommunication brand pages, and two posts belonged to jewelry and watches. In terms of post types, 234 posts were emotional posts, 205 posts were brand-related information posts, 197 posts were brand-unrelated information posts, 176 posts were entertaining posts, and 43 posts were social posts. Retail food, electronics, fashion, finance, jewelry and watches, and retail brand pages frequently posted brand-related information. Brandunrelated information appeared quite often on telecommunications, financial, and jewelry and watches brand pages. FMCG and telecommunication brands heavily adopted emotional posts. Only ecommerce brands mainly posted fun, relaxing, and entertaining content.

\subsection{Hypothesis Testing Results}

Table 2. Results of Simple Regression Analysis

\begin{tabular}{llcl}
\hline Dependent Variable & Independent Variables & $R^{2}$ & $\beta$ \\
\hline The Sum of Likes & Total Posts & .372 & $.610^{* * *}$ \\
\hline The Sum of Comments & Total Posts & .066 & $.257^{* * *}$ \\
\hline The Sum of Shares & Total Posts & .095 & $.308^{* * *}$ \\
\hline
\end{tabular}

${ }^{*} p<.05{ }^{* * p}<.01{ }^{* * *} p<.001$

Simple linear regression was applied to explore the relationships between a week's total posts and customer engagement (the sum of likes, the sum of comments, and the sum of shares) for each brand page. Hypothesis $H 1 a, H 1 b$, and $H 1 c$ were confirmed, with $R$ square $=.372, .066$, 
and .095 orderly, as shown in Table 2.

Multiple regression analyses were also conducted to check if the total of the marketing-mix posts and other posts predicted the sum of likes, comments, shares. In applying the stepwise method, it was found that the number of marketing-mix posts and other posts significantly explained the amount of variance in the sum of likes $\left(F(2,180)=88.044, p<.001, R^{2}\right.$ $=.495, R^{2}$ Adjusted $\left.=.489\right)$. The regression showed that the level of entertaining posts and promotional posts significantly indicated the sum of likes for each brand page $(\beta=.418, t(182)=5.018, p<.001$ and $\beta=.329$, $t(182)=3.950, p<.001)$. The number of marketing-mix posts and other posts were able to explain a significant proportion of the variance in the sum of comments, $R^{2}=.151, F(1,181)=32.235, p<.001$. Promotional posts significantly predicted the total comments for each brand page, $\beta$ $=.389, t(182)=5.678, p<.001$. Also, there was a significant effect of promotional posts on the sum of shares, $\beta=.373, t(182)=5.405, p<.001$. The results of analysis indicated that the predictor was able to explain $13.9 \%$ of the variance, $R^{2}=.139, F(1,181)=29.213, p=.000$. Therefore, the results partially supported the hypotheses $H 2 a-H 2 c$ and $H 3 a-H 3 c$.

Pearson's correlation analyses also showed a positive relationship between price posts and the sum of likes $(r(181)=.423, p=.000)$, a positive relationship between promotional posts and the sum of likes $(r(181)=.651$, $p=.000$ ), a positive relationship between brand-related information posts and the sum of likes $(r(181)=.235, p=.001)$, a positive relationship between emotional posts and the sum of likes $(r(181)=.195, p=.004)$, and a positive relationship between entertaining posts and the sum of likes $(r(181)=.671, p=.004)$.

Price posts and the sum of comments were positively correlated, $r(181)$ $=.135, p=.034$. Promotional posts and the sum of comments were positively correlated, $r(181)=.389, p=.000$. Entertaining posts and the sum of comments were positively correlated, $r(181)=.221, p=.001$. Price posts and the sum of shares were significantly correlated $r(181)=.186, p$ $=.006$. Promotional posts and the sum of shares were significantly correlated, $r(181)=.373, p=.000$. Emotional posts and the sum of shares 
were significantly correlated, $r(181)=.171, p=.010$. Entertaining posts and the sum of shares were significantly correlated, $r(181)=.295, p=.000$.

Multiple regression analysis was applied to determine if customer engagement (the sum of likes, comments, and shares) significantly predicted each brand awareness and interaction in terms of People Talking About This. The regression results indicated two predictors (the sum of likes and the sum of comments), explaining $45.5 \%$ of the variance $\left(R^{2}=.455\right.$, $F(2,180)=75.245, \mathrm{p}=.000)$. The sum of likes significantly drove the highest PTAT $(\beta=.513, \mathrm{p}=.000)$ and the sum of comments increased PTAT $(\beta=.195$, $\mathrm{p}=.024)$; thus, $H 4 a-H 4 b$ was supported.

Lastly, simple linear regression was conducted to determine if the highest PTAT extended the fan base of Facebook brand pages in terms of new likes. It was found that the highest PTAT explained a significant amount of the variance in new likes per week $(F(2,180)=51.452, p=.000$, $R^{2}=.221, R^{2}$ Adjusted $\left.=.217\right)$. The highest PTAT positively increased the Facebook fan base $(\beta=.470, \mathrm{p}=.000)$, supporting $H 5$. The analyses showed no autocorrelation with the Durbin-Watson statistics between 1.5-2.5 $5^{71,72}$. Also, there were no multicollinearity problems, with the tolerance value not less than 0.1 and VIF not greater than $4^{73,74}$.

Table 3. Results of Each Hypothesis

\begin{tabular}{lll}
\hline Hypothesis & Description & Decision \\
\hline$H 1 a$ & $\begin{array}{l}\text { For each brand page, more posts increase } \\
\text { the sum of likes. }\end{array}$ & Supported \\
\hline$H 1 b$ & $\begin{array}{l}\text { For each brand page, more posts increase } \\
\text { the sum of comments. }\end{array}$ & Supported \\
\hdashline$H 1 c$ & $\begin{array}{l}\text { For each brand page, more posts increase } \\
\text { the sum of shares. }\end{array}$ \\
\hline$H 2 a$ & $\begin{array}{l}\text { For each brand page, there is a positive } \\
\text { relationship between marketing-mix posts }\end{array}$ & Supported \\
& and the sum of likes. \\
\hline H2b & $\begin{array}{l}\text { For each brand page, there is a positive } \\
\text { relationship between marketing-mix posts }\end{array}$ & Supported \\
& and the sum of comments.
\end{tabular}




\begin{tabular}{lll}
\hline Hypothesis & Description & Decision \\
\hline$H 2 c$ & $\begin{array}{l}\text { For each brand page, there is a positive Partially } \\
\text { relationship between marketing-mix posts Supported } \\
\text { and the sum of shares. }\end{array}$ \\
\hline$H 3 a$ & $\begin{array}{l}\text { For each brand page, there is a positive Partially } \\
\text { relationship between other posts and the Supported } \\
\text { sum of likes. }\end{array}$ \\
\hline F3b & $\begin{array}{l}\text { For each brand page, there is a positive Partially } \\
\text { relationship between other posts and the Supported }\end{array}$ \\
\hline$H 3 c$ & sum of comments. \\
\hline For each brand page, there is a positive Partially \\
relationship between other posts and the Supported \\
sum of shares.
\end{tabular}

Table 3 summarizes the testing of the hypotheses. The results conform to the studies in the literature. For example, impressions of fans who saw post responses based on post content and type drove Fan page engagement ${ }^{18}$. Promotional posts had a significant impact on the number of comments [26]. Customers who gained some benefit such as coupons or specific information were more willing to interact with the firm ${ }^{1}$. Brand personalityrelated content such as emotional and philanthropic content drove engagement. Using direct-informative content also enabled a company to gain clicks and potential conversions; however, this may decrease social media engagement in terms of the future reach of the fan base ${ }^{14}$.

Moreover, this study yielded some interesting results that differ from the literature. De Vries, Gensler, and Leeflang did not find informative 
brand posts and entertaining brand posts to be more popular than noninformative brand posts ${ }^{30}$. Content types did not have an influence on the number of likes and comments ${ }^{8}$. Entertainment posts did not have a significant effect on total likes ${ }^{26}$. Information-seeking and entertainmentseeking characteristics had no influence on passing viral advertising by Facebook group members and commitment in marketer-generated brand communities (MGBC) $)^{31,42}$.

In sum, this study confirms past studies, which found that more posts increased customer engagement in terms of the sum of likes, shares, and comments, respectively. Unlike some past studies, the results confirm the influence of informative content in terms of promotional posts and the effects of other content in terms of entertaining posts on customer engagement. In addition to the entertaining posts and promotional posts, price posts, emotional posts, and brand-related information posts also correlated with total post popularity. The sum of likes and comments significantly boosted the brand awareness and interaction (PTAT), which later increased the new members of a Facebook brand page.

\section{IMPLICATIONS, LIMITATIONS, AND FUTURE RESEARCH}

\subsection{Theoretical and Practical Implications}

Considering the theoretical implications, this study extends the literature by adding new aspects of content types using uses and gratifications theory and the marketing-mix theory in the research model. The relationships between these content types and the full set of customer engagement (likes, comments, and shares) were studied. The influence of customer engagement along with brand awareness and interaction (the highest PTAT) were examined. Furthermore, to our best knowledge, previous studies have not explored the impact of brand awareness and interaction and the growth of a brand page in terms of new likes. Therefore, researchers could apply this research model to explore the effect of content on other social media tools selected for social commerce rather than Facebook brand pages. 
Considering the practical implications, according to the number of pages and average fans per page in each brand category, there is still room for other brands to join Facebook fan pages to attract customers in social commerce. Secondly, the results revealed that only some brand categories (FMCG, e-commerce, and retail) regularly convey messages to maintain relationships with their customers even though those brands are already among the top 100 pages with the highest number of fans. Thus, brands in other categories should frequently create messages to enhance the impressions and engagement of their customers since more content drives more likes, comments, and shares on each brand page. Thirdly, both marketing-mix information and other gratification messages affect customer engagement. Unlike FMCG brands that focus on the marketingmix information rather than other messages, brands in the other categories present other content more than 4Ps information. Consequently, brand page administrators should balance both content types to support the various needs of their customers.

Fourthly, entertaining posts and promotional posts strongly affect customer engagement, whereas price posts, emotional posts, and brandrelated information strengthen customer engagement. Brands in different categories give importance to different content, but the common post types of all brand categories are promotional posts, product posts, and brandrelated information posts. Therefore, some missing content types, particularly entertaining content and content about promotions together with content about price, emotional content, and brand-related content, should be added to enhance the relationships of brands and their customers. Lastly, more likes and comments significantly increase brand awareness and interaction, which could generate more likes in a Facebook brand page. In addition, likes and comments from customers in a Facebook brand page could enhance the engagement of non-fans. Therefore, adding more effective content and mixing content types are crucial for successfully engaging customers in social commerce. 


\subsection{Limitations and Future Research}

The limitations of this work were that it concentrated only on Facebook brand pages in Thailand and collected just a few posts in some sub-categories of post types. Thus, the findings should be applied with caution. However, most previous research has been conducted in Western environments. According to Statista, Thailand ranked in the top three with respect to countries with the highest number of Facebook users in November $2015^{75}$. This study thus presents some valuable and interesting findings from a Southeast Asian perspective using Thailand as a case study.

This study also included some brand pages from well-known international companies operating in Thailand such as Pepsi and 3M. There were few posts in some sub-categories because these posts were collected in the peak weeks of customer awareness and interaction. Therefore, they reflected the majority and minority of content in real settings and the gap to be filled by brand administrators.

Future studies should collect posts in each sub-category and the number of Facebook pages in each brand category equally, regardless of the timeframe (one week). Fan pages in other Southeast Asian countries that have a high number of users such as Indonesia and the Philippines should be examined to increase the generalizability of the results. Comparative study of the findings from different environments should be conducted to guide effective content strategy for each country or region. More Facebook metrics such as the number of people reached and post clicks should be added to enhance customer insights for effective social commerce.

\section{CONCLUSION}

Understanding what customers give precedence to in a social platform is a key to strengthen the customer relationship strategy in social commerce $^{1}$. This study thus addressed the research questions consisting of 1) Do more posts increase total post popularity? If so, how do marketingmix information and other posts affect the sum of likes, comments, and shares? 2) Does customer engagement (the total post popularity) affect the 
brand awareness and interaction (the highest PTAT) of each brand page? and 3) Do brand awareness and interaction generate more likes on each brand page?

This research collected more than 1,500 posts of 183 Facebook brand pages in nine brand categories. The results indicated that different brand categories utilized different content for their social commerce strategy. However, the findings emphasize the importance of post frequency each week and the post types (entertaining posts, promotional posts, price posts, emotional posts, and brand-related information posts) on brand page popularity. The sum of the post popularity or customer engagement of each brand page in the most popular week was collected and further linked to each page's awareness and interaction. Awareness and interaction were found to significantly pull more fans into the brand pages.

\section{REFERENCES}

[1] C. Heller Baird, and G. Parasnis, From social media to social customer relationship management. Strategy \& Leadership, 39(5), 30-37, 2011. https://doi.org/10.1108/10878571111161507

[2] K. Lee, B. Lee, and W. Oh, Thumbs up, sales up? the contingent effect of facebook likes on sales performance in social commerce. Journal of Management Information Systems, 32(4), 109-143, 2015. https://doi.org/10.1080/07421222.2015.1138372

[3] K. Z. Zhang, and M. Benyoucef, Consumer behavior in social commerce: A literature review. Decision Support Systems, 86, 95-108, 2016. https://doi.org/10.1016/j.dss.2016.04.001

[4] X. Lin, Y. Li, and X. Wang, Social commerce research: Definition, research themes and the trends. International Journal of

Information Management, 37(3), 190-201, 2017. https://doi.org/10.1016/j.ijinfomgt.2016.06.006.

[5] Y. Kim, and J. Srivastava, Impact of social influence in ecommerce decision making, Proceedings of the ninth international conference on Electronic commerce (pp. 293-302). Minneapolis, MN, USA, 2007. https://doi.org/10.1145/1282100.1282157

[6] L. Qiu, Q. Tang, and A. B. Whinston, Two formulas for success in social media: learning and network effects. Journal of Management Information Systems, 32(4), 78-108, 2015. https://doi.org/10.1080/07421222.2015.1138368

[7] Y.-L. Hsu, Facebook as international eMarketing strategy of Taiwan 
hotels. International Journal of Hospitality Management, 31(3), 972980, 2012. https://doi.org/10.1016/j.ijhm.2011.11.005

[8] K. Chauhan, and A. Pillai, Role of content strategy in social media brand communities: A case of higher education institutes in India.

Journal of Product \& Brand Management, 22(1), 40-51, 2013. https://doi.org/10.1108/10610421311298687

[9] T. Yuki, What Makes Brands' social content shareable on Facebook?. Journal of Advertising Research, 55(4), 458-470, 2015. https://doi.org/10.2501/jar-2015-026

[10] F. Sabate, J. Berbegal-Mirabent, A. Cañabate, and P. R. Lebherz, Factors influencing popularity of branded content in Facebook fan pages. European Management Journal, 32(6), 1001-1011, 2014. https://doi.org/10.1016/j.emj.2014.05.001

[11] B. Schivinski, G. Christodoulides, and D. Dabrowski, Measuring Consumers' engagement with brand-related social-media content. Journal of Advertising Research, 56(1), 64-80, 2016. https://doi.org/10.2501/jar-2016-004

[12] X. Li, L. M. Hitt, and Z. J. Zhang, Product reviews and competition in markets for repeat purchase products. Journal of Management Information Systems, 27(4), 9-42, 2011. https://doi.org/10.2753/mis0742-1222270401

[13] E. K. Clemons, How information changes consumer behavior and how consumer behavior determines corporate strategy. Journal of management information systems, 25(2), 13-40, 2008. https://doi.org/10.2753/mis0742-1222250202

[14] D. Lee, K. Hosanagar, and H. Nair, Advertising content and consumer engagement on social media: Evidence from Facebook. Management Science, 6(11), 4967-5460. 2015. https://doi.org/10.1287/mnsc.2017.2902

[15] C. Yi, Z. Jiang, and I. Benbasat, Enticing and engaging consumers via online product presentations: The effects of restricted interaction design. Journal of Management Information Systems, 31(4), 213-242, 2015. https://doi.org/10.1080/07421222.2014.1001270

[16] G. Valerio, D. J. Herrera-Murillo, F. Villanueva-Puente, N. HerreraMurillo, and M. del Carmen Rodríguez-Martínez, The relationship between post formats and digital engagement: A study of the Facebook pages of Mexican universities. Revista de Universidad y Sociedad del Conocimiento, 12(1), 50-63, 2015. https://doi.org/10.7238/rusc.v12i1.1887

[17] P. M. Markopoulos, and E. K. Clemons, Reducing buyers' uncertainty about taste-related product attributes. Journal of Management Information Systems, 30(2), 269-299, 2013.

https://doi.org/10.2753/mis0742-1222300210 
[18] D. Lee, K. Hosanagar, and H. Nair, The effect of social media marketing content on consumer engagement: Evidence from Facebook. Available at SSRN, 2290802, 2014.

[19] A. J. Kim, and K. K. Johnson, Power of consumers using social media: Examining the influences of brand-related user-generated content on Facebook. Computers in Human Behavior, 58, 98-108, 2016. https://doi.org/10.1016/j.chb.2015.12.047

[20] E. Bonsón, S. Royo, and M. Ratkai, Citizens' engagement on local governments' Facebook sites. An empirical analysis: The impact of different media and content types in Western Europe. Government Information Quarterly, 32(1), 52-62, 2015. https://doi.org/10.1016/j.giq.2014.11.001

[21] A. T. Stephen, M. Sciandra, and J. Inman, Is it what you say or how you say it? how content characteristics affect consumer engagement with brands on Facebook. Saïd Business School WP, 19, 2015. https://doi.org/10.2139/ssrn.2683314

[22] D. E. Schultz, and J. Peltier, Social media's slippery slope: Challenges, opportunities and future research directions. Journal of Research in Interactive Marketing, 7(2), 86-99, 2013. https://doi.org/10.1108/jrim-12-2012-0054

[23] E. K. Clemons, S. Barnett, and A. Appadurai, The future of advertising and the value of social network websites: Some preliminary examinations. Proceedings of the ninth international conference on Electronic commerce (pp. 267-276). Minneapolis, MN, USA, 2007. https://doi.org/10.1145/1282100.1282153

[24] I. P. Cvijikj, and F. Michahelles, Online engagement factors on Facebook brand pages. Social Network Analysis and Mining, 3(4), 843-861, 2013. https://doi.org/10.1007/s13278-013-0098-8

[25] V. K. Singh, R. Jain, and M. Kankanhalli, Mechanism design for incentivizing social media contributions, In Springer (Ed.), Social media modeling and computing (pp. 121-143). 2011. https://doi.org/10.1007/978-0-85729-436-4_6

[26] B. Shen, and K. Bissell, Social media, social me: A content analysis of beauty companies' use of Facebook in marketing and branding. Journal of Promotion Management, 19(5), 629-651, 2013. https://doi.org/10.1080/10496491.2013.829160

[27] Socialbakers.com. (2014). A marketer's guide to Facebook metrics. Available:

http://www.socialbakers.com/resources/studies/amarketers-guide-tofacebook-metrics

[28] G. Pitts, and C. Aylott, Opening pandora's box: The challenge of social media in a regulated environment. Journal of Securities Operations \& Custody, 5(3), 251-261, 2013. 
[29] W. S. Chow, and S. Shi, Investigating customers' satisfaction with brand pages in social networking sites. Journal of Computer Information Systems, 55(2), 48-58, 2015. https://doi.org/10.1080/08874417.2015.11645756

[30] L. De Vries, S. Gensler, and P. S. Leeflang, Popularity of brand posts on brand fan pages: An investigation of the effects of social media marketing. Journal of Interactive Marketing, 26(2), 83-91, 2012. https://doi.org/10.1016/j.intmar.2012.01.003

[31] S.-C. Chu, Viral advertising in social media: participation in Facebook groups and responses among college-aged users. Journal of Interactive Advertising, 12(1), 30-43, 2011. https://doi.org/10.1080/15252019.2011.10722189

[32] W.-M. Hur, K.-H. Ahn, and M. Kim, Building brand loyalty through managing brand community commitment. Management Decision, 49(7), 1194-1213, 2011. https://doi.org/10.1108/00251741111151217

[33] J. W. Ping, K. Y. Goh, Z. Lin, Q. Goh, and A. Chih, Does Social media brand community membership translate to real sales? A critical evaluation of purchase behavior by fans and non-fans of a Facebook fan page. Proceedings ofthe 20th European Conference on Information Systems, Barcelona, Spain, 2012.

[34] E. Bonsón, and M. Ratkai, A set of metrics to assess stakeholder engagement and social legitimacy on a corporate Facebook page, Online Information Review, 37(5), 787-803, 2013. https://doi.org/10.1108/oir-03-2012-0054

[35] N. Hajli, Social commerce constructs and consumer's intention to buy. International Journal of Information Management, 35(2), 183-191, 2015. https://doi.org/10.1016/j.ijinfomgt.2014.12.005

[36] T. Hennig-Thurau, K. P. Gwinner, G. Walsh, and D. D. Gremler, Electronic word-of-mouth via consumer-opinion platforms: What motivates consumers to articulate themselves on the Internet?.

Journal of interactive marketing, 18(1), 38-52, 2004. https://doi.org/10.1002/dir.10073

[37] S. Koch and Ö. Elçiseven, A theoretical framework for assessing effects of user generated content on a company's marketing outcomes, Proceeings of International Conference on Information Resources Management (CONF-IRM), Vienna, Austria, 2012.

[38] X. Luo, and J. Zhang, How do consumer buzz and traffic in social media marketing predict the value of the firm?. Journal of Management Information Systems, 30(2), 213-238, 2013. https://doi.org/10.2753/mis0742-1222300208

[39] E. Katz, J. G. Blumler, and M. Gurevitch, Utilization of mass communication by the individual. Sources notable selections in 
mass media, 51-59, 1999.

[40] T.-P. Liang, H.-J. Lai, and Y.-C. Ku, Personalized content recommendation and user satisfaction: Theoretical synthesis and empirical findings. Journal of Management Information Systems, 23(3), 45-70, 2006. https://doi.org/10.2753/mis0742-1222230303

[41] M. J. de Oliveira, M. K. Z. Huertas, and Z. Lin, Factors driving young users' engagement with Facebook: Evidence from Brazil, Computers in Human Behavior, 54, 54-61, 2016. https://doi.org/10.1016/j.chb.2015.07.038

[42] H.-S. Chiang, Continuous usage of social networking sites: The effect of innovation and gratification attributes. Online Information Review, 37(6), 851-871, 2013. https://doi.org/10.1108/oir-08-2012-0133

[43] A. Quan-Haase, and A. L. Young, Uses and gratifications of social media: A comparison of facebook and instant messaging. Bulletin of Science, Technology \& Society, 30(5), 350-361, 2010. https://doi.org/10.1177/0270467610380009

[44] N. Park, K. F. Kee, and S. Valenzuela, Being immersed in social networking environment: Facebook groups, uses and gratifications, and social outcomes. CyberPsychology \& Behavior, 12(6), 729-733, 2009. https://doi.org/10.1089/cpb.2009.0003

[45] A. Whiting, and D. Williams, Why people use social media: A uses and gratifications approach. Qualitative Market Research: An International Journal, 16(4), 362-369, 2013. https://doi.org/10.1108/qmr-06-2013-0041

[46] Y. Sung, Y. Kim, O. Kwon, and J. Moon, An explorative study of Korean consumer participation in virtual brand communities in social network sites, Journal of Global Marketing, 23(5), 430-445, 2010. https://doi.org/10.1080/08911762.2010.521115

[47] K. Swani, G. Milne, and B. P. Brown, Spreading the word through likes on Facebook: Evaluating the message strategy effectiveness of Fortune 500 companies. Journal of Research in Interactive Marketing, 7(4), 269-294, 2013. https://doi.org/10.1108/jrim-05-2013-0026

[48] M. Mostaani, The management of consumer cooperatives, Paygan Publications, Tehran, 2005.

[49] E. Constantinides, The marketing mix revisited: Towards the $21 \mathrm{st}$ century marketing. Journal of marketing management, 22(3-4), 407438, 2006. https://doi.org/10.1362/026725706776861190

[50] M. Zineldin, and S. Philipson, Kotler and Borden are not dead: Myth of relationship marketing and truth of the 4Ps. Journal of consumer marketing, 24(4), 229-241, 2007.

https://doi.org/10.1108/07363760710756011 
[51] C. L. Goi, A review of marketing mix: 4Ps or more?. International Journal of Marketing Studies, 1(1), 2009. https://doi.org/10.5539/ijms.v1n1p2

[52] M. K. Jain, An analysis of marketing mix: 7Ps or more. Asian Journal of Multidisciplinary Studies, 1(4), 23-28, 2013.

[53] W. Davies, and K. E. Brush, High-tech industry marketing: The elements of a sophisticated global strategy. Industrial Marketing Management, 26(1), 1-13, 1997. https://doi.org/10.1016/s0019-8501(96)00073-9

[54] S. Manickam, and B. Sriram, Modeling the impact of marketing information on consumer buying behavior in a matured marketing environment: An exploratory study of the middle east consumers, Journal of Promotion Management, 19(1), 1 -16, 2013. https://doi.org/10.1080/10496491.2012.715127

[55] K.-Y. Goh, C.-S. Heng, and Z. Lin, Social media brand community and consumer behavior: Quantifying the relative impact of user-and marketer-generated content. Information Systems Research, 24(1), 88107, 2013. https://doi.org/10.1287/isre.1120.0469

[56] A. Malhotra, C. K. Malhotra, and A. See, How to create brand engagement on Facebook. MIT Sloan Management Review, 54(2), 18$20,2013$.

[57] J. Chen, and X.-L. Shen, Consumers' decisions in social commerce context: An empirical investigation. Decision Support Systems, 79, 5564, 2015. https://doi.org/10.1016/j.dss.2015.07.012

[58] U. M. Dholakia, R. P. Bagozzi, and L. K. Pearo, A social influence model of consumer participation in network-and small-group-based virtual communities. International journal of research in marketing, 21(3), 241-263, 2004. https://doi.org/10.1016/j.ijresmar.2003.12.004

[59] J. Raacke, and J. Bonds-Raacke, MySpace and Facebook: Applying the uses and gratifications theory to exploring friend-networking sites. Cyberpsychology \& behavior, 11(2), 169-174, 2008. https://doi.org/10.1089/cpb.2007.0056

[60] D. G. Muntinga, M. Moorman, and E. G. Smit, Introducing COBRAs. International Journal of Advertising, 30(1), 13-46, 2011. https://doi.org/10.2501/ija-30-1-013-046

[61] K.-Y. Lin, and H.-P. Lu, Why people use social networking sites: An empirical study integrating network externalities and motivation theory, Computers in Human Behavior, 27(3), 1152- 1161, 2011. https://doi.org/10.1016/j.chb.2010.12.009

[62] R. Kivetz, and I. Simonson, The effects of incomplete information on consumer choice. Journal of Marketing Research, 37(4), 427- 448, 2000. https://doi.org/10.1509/jmkr.37.4.427.18796 
[63] S. Brown, R. V. Kozinets, and J. F. Sherry Jr, Teaching old brands new tricks: retro branding and the revival of brand meaning. Journal of Marketing, 67(3), 19-33, 2003. https://doi.org/10.1509/jmkg.67.3.19.18657

[64] A. Susarla, J.-H. Oh, and Y. Tan, Influentials, imitables, or susceptibles? virality and word-of-mouth conversations in online social networks. Journal of Management Information Systems, 33(1), 139-170, 2016. https://doi.org/10.1080/07421222.2016.1172454

[65] J. Phua, S. V. Jin, and J. J. Kim, Gratifications of using Facebook, twitter, instagram, or snapchat to follow brands: The moderating effect of social comparison, trust, tie strength, and network homophily on brand identification, brand engagement, brand commitment, and membership intention. Telematics and Informatics, 34(1), 412-424, 2017. https://doi.org/10.1016/j.tele.2016.06.004

[66] I. Othman, A. Bidin, and H. Hussain, Facebook marketing strategy for small business in Malaysia. Proceedings of Informatics and Creative Multimedia (ICICM), International Conferences (pp. 236-241), Kuala Lumpur, Malaysia, 2013. https://doi.org/10.1109/icicm.2013.66

[67] J. Zhang, Y. Wu, H. Liang, Q. Gu, A. Mack, and A. Tsipenyuk, Method and system for creating targeted advertising utilizing social media activity. US Patents, US13368515, 2012.

[68] Socialbakers.com. (2013). Pages in Thailand. Available: http://www.socialbakers.com/facebook-pages/brands/thailand/

[69] Socialbakers.com. (2013). February 2013 Social marketing report: Thailand. Available: http://www.socialbakers.com/blog/1515february-2013-social-media-report-facebook-pages-in-thailand

[70] J. Carlson, P. J. Rosenberger III, and S. Muthaly, Goal!: An exploratory study of the information content in the Australian National Soccer League websites, Paper Presented at the Australian and New Zealand Marketing Academy Conference, Massey University Albany Campus, Auckland New Zealand, 2001.

[71] N. A. Wahid, E. Rahbar, and T. S. Shyan, Factors influencing the green purchase behavior of Penang environmental volunteers. International Business Management, 5(1), 38-49, 2011. https://doi.org/10.3923/ibm.2011.38.49

[72] A. Büyüksalvarci and H. Abdioglu, Determinants of capital adequacy ratio in Turkish Banks: A panel data analysis. African Journal of Business Management, 5(27), 11199-11209, 2011.

[73] J. Miles, Tolerance and variance inflation factor, Wiley StatsRef: Statistics Reference Online, 2009. 
[74] M. van Vuuren, M. D. de Jong, and E. R. Seydel, Direct and indirect effects of supervisor communication on organizational commitment. Corporate Communications: An International Journal, 12(2), 116128, 2007. https://doi.org/10.1108/13563280710744801

[75] Statista.com. (2016). Number of Facebook users in Southeast Asia as of November 2015, by country (in millions). Available: https://www.statista.com/statistics/193056/facebook-usernumbers-inasian-countries/ 